\title{
ADVANTAGES OF PLASTINATED HUMAN BODY IN MEDICAL EDUCATION AND ITS LEGAL \& ETHICAL ASPECTS
}

\author{
R. K. Chaturvedi ${ }^{1}$, Anurag Singh ${ }^{2}$, Praveen Chaturvedi ${ }^{3}$, Abha Mishra $^{4}$, S. P. Mishra ${ }^{5}$
}

\section{HOW TO CITE THIS ARTICLE:}

R. K. Chaturvedi, Anurag Singh, Praveen Chaturvedi, Abha Mishra, S. P. Mishra. "Advantages of Plastinated Human Body in Medical Education and its Legal \& Ethical Aspects". Journal of Evolution of Medical and Dental Sciences 2014; Vol. 3, Issue 10, March 10; Page: 2626-2631, DOI: 10.14260/jemds/2014/2184

ABSTRACT: Plastination is a scientific procedure or technique of preservation of body or body parts useful in anatomy and forensic medicine department for medical education. Exhibition of preserved human body and body parts, that are prepared using a plastination technique revealing inner anatomical structures, is called Body Worlds (German title: "Körperwelten"). The use of plastinated specimens has greatly assisted students in their understanding of anatomy and gross pathology and their being able to correlate these specimens with radio graphical images of the human body. Several ethical and legal questions may arise while considering adoption of a plastinated human body as teaching tools in medical education. Here, we have focused our attention over basic scientific concepts with legal and ethical issues in relation to use of plastinated human bodies in medical education.

KEYWORDS: Plastination Technique, Medical Education, Learning Methodology.

INTRODUCTION: Plastination is a scientific procedure or technique of preservation of body or body parts useful in anatomy and forensic medicine departments for medical education. ${ }^{1}$ Under this technique, the water and fat of the body are replaced by certain plastic yielding specimens that can be touched, do not smell or decompose, and even retain most properties of the original sample ${ }^{2}$. The plastination technique offers a unique advantage over all the other techniques, as it permits the display of internal organs that are dry and close to the living state. And these organs can be placed into skeletons to enhance their teaching value. In November 1979, Gunther Von Hagens at the University of Heidelberg first time applied this procedure for preserving animal and vegetable tissues permanently by synthetic resin impregnation.

Exhibition of preserved human bodies and body parts that are prepared using a plastination technique reveal inner anatomical structures is called Body Worlds (German title: "Körperwelten") 3 .

Other different methods had been in use for thousands of years to preserve the decomposition of the body, out of those, mummification used by the Egyptians is a widely known method which involves the removal of body fluid and wrapping the body in linens. Prior to mummification, Egyptians used to lay the body in a shallow pit in the desert and allow the sun to dehydrate the body.

Formalin, an important solution to body preservation, was introduced in 1896, soon after formalin, color preserving embalming solutions were introduced to preserve normal body color and flexibility to enhance better demonstration in the study of the body in medical education. ${ }^{4}$

Other techniques of body preservation methods are cryopreservation which involves the cooling of the body to very low temperatures to preserve the body tissues, plastination and embalming techniques. 
BASIC PROCEDURES OF PLASTINATION TECHNIQUE: There are four integrated basic steps are utilized in the process of the plastination technique: specimen preparation and fixation, dehydration, forced impregnation in a vacuum and hardening. In this technique, water and lipid tissues are replaced by curable polymers like silicone, epoxy and polyester-copolymer. ${ }^{5}$

Usually, high quality specimens with proper dissection are needed to form plastinated body. Hollow organs need to be flushed, cleaned, dilated and then fixed in a dilated position. Dilation of hollow organs will increase the flexibility of that organ by overcoming rigor. Intestinal specimens may be opened to remove ingest, sutured closed and then dilated. Ostia with strong sphincters must be held open with appropriate sized cannulas or by tubing. All cut vessels of heart preparations must be closed by ligatures or inverted corks ligated in place, except for one vena cava and one pulmonary vein. Vena cava and pulmonary vein will have tubing ligated in place and are used for dilating each side of the heart. Intravascular injection of colored silicone, gelatin, latex or epoxy may be used to highlight vessels. ${ }^{6}$

(A) Specimen Preparation and Fixation: It is necessary to prepare high quality dissected specimen to produce plastinates. Under fixation, the body is embalmed, usually in a formaldehyde solution in order to prevent the decomposition of the body. Specimens may be fixed prior to or after prosection. However, to minimize exposure to formalin vapors and to assure final specimen shape and desired position, fixation should be done after prosection. Usually $10 \%$ formaldehyde solution may be used as a fixative, lower percentage formalin solutions may produce less bleaching of the specimen. However, brain should be fixed with high (10-20) percentage formalin for several months in order to prevent the shrinkage during impregnation. ${ }^{7}$ Minimal fixation with low percentage of formalin and short time duration (1-2 days) will yield a specimen which is more flexible and more natural looking. Fixation of hollow organs is necessary to maintain the shape and lumen of the organ. It is beneficial to keep the specimen in its normal anatomical position during both, fixation as well as in the first dehydration bath. ${ }^{3}$

(B) Dehydration: All biological specimens, generally, have a high water content which needs to be removed for plastination procedure. This is achieved by a process known as dehydration, where the specimens are placed into cold ( -25 degree centigrade) solvent, usually acetone for four to five weeks. Over a period of four to five weeks, the tissue water is slowly replaced by the acetone. It would be easy to dilate maximally the body organs in freezing acetone during the initial exposure to acetone. This freezes the organ in a dilated state and assures maximal dilation of the organ later on in the plastination process. ${ }^{4}$

(C) Impregnation: In the third step, the dehydrated specimen is then placed in a bath of liquid polymer, such as silicone rubber, polyester or epoxy resin. By creating a vacuum, the acetone is made to boil at a low temperature. The vacuum draws out the acetone from the specimen and the polymer, takes its place inside the tissues and vessels..$^{4,5}$

(D) Hardening: The impregnated specimen is cured with gas, heat, or ultraviolet light, in order to harden it. The polymer filled specimen is placed into a sealed chamber where it comes in contact with a curing gas. This gas will harden the polymer throughout the specimen, making the specimen dry to 
touch within 48 hours. In a few months, curing procedure is completed and the specimen can be stored indefinitely at room temperature.

Other methods used in modern times include the Silicone S-10 Standard Procedure, the CorTech Room temperature procedure, the Epoxy E-12 procedure, and the Polyester P-35 (P-40) procedure. The Silicone S-10 is the procedure, most often used in plastination and it provides opaque, natural-looking specimen. Cor -Tech Room Temperature Procedure is designed to allow plastination of specimen at room temperature to various degrees of flexibility using three combinations of polymer, cross linker and catalyst. According to the International Society for Plastination, the Epoxy E-12 procedure is utilized for thin, transparent, and firm body and organ slices, while the Polyster P-5 or P-40 preserves semitransparent and firm brain slices. ${ }^{4,5}$

Plastinated Human Body and Specimens and its Advantages in Medical Education: The use of plastinated specimens has greatly assisted students in their understanding of anatomy and gross pathology and their being able to correlate these specimens with radio graphical images of the human body. Now a days, most of the teaching faculty in medical colleges are using power point presentation (which shows colored pictures and diagrams during the lectures) if plastinated specimens are available to students in these lectures, they will have a real time experience of human anatomy and pathology without having any issue of spoiling their clothes, own hands and the toxic irritant smell of formalin. So they can make relevant notes after handling plastinated specimens as there is no issue of washing the hands and changing the gloves. ${ }^{8}$.

The plastinated specimen is easy to handle, more robust, chemical free and can be easily stored. Students tend to find plastinated specimens more pleasant to handle than wet specimens. Using these plastinated specimens, institution can establish self-directed learning stations which the students may use for their study of anatomy and forensic pathology. ${ }^{9}$

The plastinated specimens are more flexible, durable, and life like. Over the next two years, Von Hagens developed the Körperwelten (BODY WORLDS) public exhibitions, showing whole body plastinated in life like poses and dissected to show various structures and systems of human anatomy. ${ }^{10}$ So plastination is useful in medical education as serving models and teaching tools, because it allows students to interpret three dimensional picture with exact interpretation of the shape and size in this field and for example, plastinated gastrointestinal tracts are used to help in the teaching of endoscopic technique and anatomy. ${ }^{11}$

The exhibit stated that its purpose and mission were the education of laymen about the human body, leading to better health awareness. ${ }^{7}$ All the human plastinates are from people who donated their bodies for plastination via a body donation program. Some of the specimens, such as the Tai Chi Man, demonstrate interventions, and include prosthetics such as artificial hip joints or heart valves.

Gary Whittaker Currently employed at Curtin as Senior Lab Tech/Prosectionist and Tutor for the Department of Human Biology, School of Biomedical Sciences stated that Plastinated specimens, prepared in many institutions worldwide, have been widely accepted particularly due to their hardwearing, durable nature and their high teaching value and are useful not only in the subject of medical education but also have academic value in the science subject like zoology, botany and anthropology. 12 
Plastinated Specimens and its Limitation in Medical Education: Plastinated specimens also have their limitations, as they are relatively inflexible and structures cannot be manipulated or easily reflected to reveal underlying anatomical gross structures and features. Dissection after plastination is also limited but with careful tissue preparation before plastination an extremely useful and somewhat superior specimen can be produced. ${ }^{13}$

Plastinated Human Body in Medical Education and its Ethical Aspects: Several ethical and legal questions may arise while considering adoption of a plastinated human body as teaching tools in medical education like ${ }^{14-16}$

- Can this technology be indicated in medical education?

- What are the benefits of showing plastinated body in college demonstration room?

- Does it improve medical knowledge of students?

- Does it bring about better learning methodology in medical education?

- Whether donor consent is sufficient to accept body after death for plastination or it needs consent from guardian also.

- The early step of Plastination is academic autopsy, whether people will agree and give consent for own dissection or they think; it is terrible to be skinned and cut into slices?

- For making plastinated body, whether we need death certificate issued by medical doctor and state or not?

- What would be the cost of this technology? Is it cost effective as compared to other alternative technology?

Plastination has led to a major expansion in a range of Anatomical specimens available for teaching. Its potential value in research is being appreciated. In the West, it has been shown to the public arena through an exhibition termed "Anatomical Art" where plastinated models had been displayed showing various normal and pathological specimens. However, this exhibition raised an ethical debate about display of human specimens for entertainment or non-educational purposes.(11)(12) The only rationale and logic behind such a display could be an educational one. This also brought into focus the large amount of human material stored in Archives and Museums. So, strict legislative regulation is required to control exhibition, storage and preparation of plastinated body.

Therefore, in the absence of teaching or research rationale, there are no ethical preset rules for disposing or storing it. This regulation is required to control storage of all human specimens, constant reappraisal of ethical and moral issues from the society are also needed from time to time for upgrading and implementing this procedure for education; appropriate relevant evolving legislature and re-evaluation is the only solution. A Paradigm shift is required for Anatomists and Forensic experts to contribute to this ethical debate not only as custodians of the dead but also protectors of the living.

Some critics have questioned the educational value of plastinated human body and specimens. Other alternative methods like Color-coded casts of the specimens have proven invaluable for teaching medical gross anatomy. By acquiring greater understanding of the spatial relationship of overlapping organs, circulatory vessels and the lobes of the lungs, students are better equipped to efficiently and accurately examine patients and to interpret diagnostic images of the body system. 
The anatomical accuracy and durability of plastinates make them powerful tools to accelerate knowledge acquisition and strengthens diagnostic abilities for medical students utilizing a wider variety of learning strategies.

Concern over consent of bodies being used in the plastination process has arisen. Over 20 years ago, Von Hagens set up a body donation program in Germany and has signed over 9, 000 donors into the plastinate program and he followed strict consent procedures for whole-body specimens, does this consent is sufficient for different body parts, dissection and preparation for plastination? He stated that consent is not important for body parts. Most of people, even after filling donor form for plastination, don't think of autopsy or of being skinned in connection with plastination. The reason is that the words autopsy or dissection or skinning have a negative meaning in the moral society. Many donors want to be plastinated as a whole body; they don't like the idea of their body being sliced or their body being skinned. Several spectators were against the display of plastinated bodies and thought it was dehumanizing and deceased ones should not be made center of attraction for sake of public or education. There were comments like "When you die, you should be allowed to die, not carted around the world as a laminated corpse and rest in peace and not in pieces".

International trade experts and ethicist have objected to the way in which bodies for commercial display are imported, because the way their categorization codes (as "art collections") do not require permission from health ministry of any country or death certificates issued by doctor, both of which are required for medical cadavers. In most countries plastinated human specimens are classified under Customs Classification Code 97050000.48 "items in anatomical collections". This customs code encompasses "zoological, botanical, mineralogical or anatomical collections or items in such collections." 17

CONCLUSIONS: The plastinated specimens will bring tridimensionality to teaching in the form of clean, touchable, authentic, non-smelly, non-toxic, non-bio-hazardous specimens. It has been found that plastinated specimens are superior to those preserved in formalin for teaching pathology to undergraduate medical students. Commercial display should be discouraged on ethical and legal grounds. Advantages and disadvantages over other methods, along with legal and moral aspects must be kept in front of society for integrating with medical education of the nation.

\section{REFERENCES:}

1. Von Hagens, Gunther; Klaus Tiedemann and Wilhelm Kriz. The current potential of plastination". Anatomy and Embryology 1987; 175 (4): 411-21.doi:10.1007/BF00309677.

2. Weiglein, A. H. Overview \& General Principles of the Plastination Procedures". 8th Interim Conf Plast(Ohrid). Retrieved 27 January 2009.

3. Current Exhibitions, Denver Museum of Nature and Science. Retrieved 2010-05-19.

4. Henry, Robert W.; Larry Janick and Francis Paul Salmos (February 1997). "Specimen preparation for silicone plastination". Journal of the International Society for Plastination 12 (1). ISSN 1090-2171. Retrieved 27 January 2009.

5. Bickley, Harmon C.; Robert S. Conner, Anna N. Walker and R. Lamar Jackson (January 1987)."Preservation of tissue by silicone rubber impregnation". Journal of the International Society for Plastination 1 (1): 30-39. ISSN 1090-2171. Retrieved 10 May 2009. 
6. Moore CM, Brown CM: Gunther von Hagens and Body Worlds, Part 2: the anatomist as priest and prophet. Anat Rec (New Anat) 277B:14-20, 2004.

7. Lozanoff S.2002.Revisiting Anatomy: Impact of Plastination on how we see human body. Clin Anat 20 nov, 15(6):441-2.

8. Dhingra R, Taranikanti V, Kumar R. 2006.Teaching aids in Anatomy Revisited. Natl Med J India May- Jun, 19(3): 171.

9. Mehta A.V. A review on Plastinated Process, Uses and Ethical IssuesVol.7No2(2007) MedicoLegal Update.

10. Holladay SD, Hudson LC (1989). "Use of plastinated brains in teaching neuroanatomy at the North Carolina State University, College of Veterinary Medicine". Journal of the International Society for Plastination 3 (1): 15-17. Retrieved 19 May 2009.

11. von Hagens G, Whalley A: BODY WORLDS - The Anatomical Exhibition of Real Human Bodies. Institut für Plastination, Heidelberg, Germany, $5^{\text {th }}$ Printing 2004 (Translation in English of 14 th German Printing).

12. "Pathology Academic Resource Center: UT Health Science Center - Graduate School of Biomedical Science". Pathology.uthscsa.edu. Retrieved 2010-09-22.

13. Myser, C. Taking public education seriously: BODY WORLDS, the science museum, and democratizing bioethics education. Am. J. Bioeth., 7:34-6, 2007.

14. Ashcroft R. 2000. Ethics of reusing archived tissue for research. Neuropathol Appl Neurobiol Oct 26(5): 408-11.

15. Hawley D. A, Marlin D.C, Cook, Becsey D, Clark M.A., Pless J.E., Standish S.M. 1991. Specimens for teaching Forensic pathology, Odontology and Anthropology. Am J For Med Pathol Jun, 12(2): 164-9.

16. Satyapal KS. 2005. Ethics, Transplantation and changing role of Anatomists.Clin Anat March, 18(2): 150-3.

17. Singh, Debashis; Von Hagens, G (March 2003). "Scientist or showman. BMJ 326 (7387): 468. doi:10.1136/bmj.326.7387.468. PMC 1125369.

\section{AUTHORS:}

1. R. K. Chaturvedi

2. Anurag Singh

3. Praveen Chaturvedi

4. Abha Mishra

5. S. P. Mishra

\section{PARTICULARS OF CONTRIBUTORS:}

1. Associate Professor, Department of Forensic Medicine, SAIMS, Indore, M. P, India.

2. Professor and HOD, Department of Anatomy, GRRIMS, Dehradun, U. K, India.

3. Resident, Department of Ophthalmology, IMS, BHU, Varanasi, U. P, India.

4. Resident, Department of Pathology, SSMC, Rewa, M. P, India.
5. Assistant Professor, Department of Biochemistry, IMS, BHU, Varanasi, U. P, India.

\section{NAME ADDRESS EMAIL ID OF THE CORRESPONDING AUTHOR:}

Dr. R. K. Chaturvedi,

Department of Forensic Medicine \& Toxicology,

SAIMS, Indore, M. P.

E-mail: drrajeshchaturvedi@rediffmail.com

Date of Submission: 03/02/2014.

Date of Peer Review: 04/02/2014.

Date of Acceptance: 19/02/2014.

Date of Publishing: 07/03/2014. 